\title{
Vitamin D deficiency - a possible link between osteoporosis and metabolic syndrome
}

\author{
Brazdilova K, Dlesk A, Koller T, Killinger Z, Payer J \\ 5th Department of Internal Medicine, Medical Faculty of Comenius University and University Hospital Bratislava, \\ Bratislava, Slovakia. kristina.brazdilova@gmail.com
}

\begin{abstract}
Objectives: The aim of our study was to evaluate the relationship between bone mineral density (examined by DXA - dual energy x-ray absorptiometry), vitamin $\mathrm{D}_{3}$ levels and the signs of metabolic syndrome. Methods: We examined 55 subjects (37 women, 18 men, age median 67.8 years) with no history of osteoporosis, suffering from metabolic syndrome (defined as abdominal obesity and more than 2 of other components arterial hypertension, dyslipidemia and diabetes mellitus or impaired glucose tolerance, according to IDF, 2006). Results: Osteoporosis (T-score less than - 2.5) was found in $32.7 \%$ (15 women and 3 men) and osteopenia (T-score between - 1.5 and - 2.5) in $29 \%$ (13 women and 3 men) of patients. We observed a negative correlation between BMI and fat percentage (examined by DXA) and vitamin $D_{3}$ levels. Low concentration of vitamin $D_{3}$ was found in $90 \%$ of patients with median $19.36 \mathrm{ug} / \mathrm{l}(64 \%$ measured in winter, $36 \%$ in summer, no relationship between vitamin $D_{3}$ levels and season). We also observed a negative correlation between the low concentration of vitamin $D_{3}$ and presence of diabetes mellitus as a part of metabolic syndrome.

Conclusion: The link between osteoporosis and metabolic syndrome could influence the therapeutic approach in both disorders and vitamin D supplementation may play an important role in prevention of these severe conditions (Tab. 5, Fig. 1, Ref. 29). Full Text in PDF www.elis.sk.

Key words: osteoporosis, dual energy x-ray absorptiometry, vitamin D, metabolic syndrome.
\end{abstract}

\begin{abstract}
Abbreviations: DXA - dual energy x-ray absorptiometry, IDF - International Diabetes Federation, BMI - Body Mass Index, WHO - World Health Organisation, NCEP-ATP - National Cholesterol Education Program; Third Adult Treatment Panel, 25 $(\mathrm{OH})$ vitamin $\mathrm{D}-25$-hydroxyvitamin $\mathrm{D}, 1,25(\mathrm{OH})_{2}$ vitamin $\mathrm{D}$ - 1,25-dihydroxyvitamin D, PTH - parathormone, Ca - calcium, LDL - low-density lipoprotein, HDL - high-density lipoprotein, TAG - triacylglyceride, BMD - Bone Mineral Density, SD Standard Deviation, DM - Diabetes Mellitus, CARDIA-Coronary Artery Risk Development in Young Adults, NHS - Nurses Health Study, HPFS - Health Professionals' Follow-up Study.
\end{abstract}

Osteoporosis and metabolic syndrome, two multifactorial disorders, are medical problems with a major epidemiological dimension. Several common pathophysiological factors for both entities have been suggested. These include many factors (lipid oxidation products, inflammatory factors, estrogens, parathormone) and vitamin $\mathrm{D}$ deficiency could be one of the most important one.

\section{Osteoporosis}

Osteoporosis is an important health problem with major epidemiological dimension. It is defined as a progressive systemic skeletal

5th Department of Internal Medicine, Medical Faculty of Comenius University and University Hospital Bratislava, Bratislava, Slovakia

Address for correspondence: K. Brazdilova, MD, 5th Dept of Internal Medicine, Pazitkova 4, SK-821 01 Bratislava, Slovakia.

Phone: +421.908191504
Tab. 1. Decrease of bone density can be divided into 3 main groups (1).

Osteopenia decrease of bone density that leads to osteopo-
rosis (praeclinical osteoporosis) with mild increased risk of fracture (T-score -1.0 to -2.5 )

Osteoporosis without $\quad$ T-score below Vitamin D metabolism (Fig.1) pathologic fracture (6): 2.5

Osteoporosis with T-score below -2.5 and $1-3$ vertebral fractures pathologic fracture without adequate trauma

Severe osteoporosis decrease of bone density, multiple vertebral fractures and frequent nonvertebral fractures

disorder characterised by decrease of bone mass and impaired microarchitecture of bone tissue predisposing a person to an increased risk of fracture. The WHO Working Group defines osteoporosis according to measurements of bone mineral density (BMD) using dual energy x-ray absorptiometry (DXA). Thu, osteoporosis is defined as a bone density T-score at or below 2.5 standard deviations (T-score) below normal peak values for young adults (1) (Tab. 1).

A metaanalysis of large clinical studies by the WHO affiliated working group has considered the following as the most significant risk factors:

1. Osteoporosis risk factors unmodifiable: genetic predisposition - a higher risk in Caucasians and patients with a family history of osteoporosis fractures and thin stature; age; gender-more significant risk in women compared to men.

2. Osteoporosis risk factors modifiable (WHO Scientific Group 2007) (2): physical activity; physical inactivity - inactivity-induced 
Tab. 2. NCEP-ATP III (National Cholesterol Education Program; Third Adult Treatment Panel) (2001) (4).

It requires at least three of the following:

1. waist circumference $>102 \mathrm{~cm}$ in male and $>88 \mathrm{~cm}$ in female

2. blood pressure $>130 / 85 \mathrm{mmHg}$

3. fasting plasma glucose $>6.0 \mathrm{mmol} / 1$

4. triglycerides $>1.7 \mathrm{mmol} / 1$

5. high-density lipoprotein cholesterol $<1.25 \mathrm{mmol} / 1$ (female) or 1.0 $\mathrm{mmol} / \mathrm{l}$ (male)

Tab. 3. IDF (International Diabetes Federation) (2006) (4).

Waist circumference + at least two of the following - arterial hypertension, dyslipidemia, diabetes mellitus or impaired glucose tolerance)

\begin{tabular}{lll}
\hline Normal waist circumference: & Men & Women \\
\hline Europe, USA & $<94 \mathrm{~cm}$ & $<80 \mathrm{~cm}$ \\
South Asia, China & $<90 \mathrm{~cm}$ & $<80 \mathrm{~cm}$ \\
Japan & $<85 \mathrm{~cm}$ & $<90 \mathrm{~cm}$ \\
\hline
\end{tabular}

osteoporosis develops during a complete immobilization. Depending of the intensity of bone metabolism in the individual patient, significant loss of bone mineral density occurs over weeks to months. Dietary supply of calcium-insufficient supply of calcium, a disturbance of its absorption from the gastrointestinal tract and increased excretion in the kidneys may lead to a negative calcium balance and increased bone loss. Body weight - reduced body weight, often combined with other risk factors, increases the risk of postmenopausal osteoporosis. The BMI $<19 \mathrm{~kg} / \mathrm{m}^{2}$ is an important risk factor for fractures.

3. Diseases that leads to secondary osteoporosis (3): hypogonadal states (Turner syndrome, Klinefelter syndrome, anorexia nervosa, hypothalamic amenorrhea, hyperprolactinemia, prolonged premenopausal amenorrhea $>1$ year, early menopause $<45$ years, bilateral oophorectomy, premature ovarial failure, testosterone deficiency in men), endocrine diseases (Cushing's syndrome, hyperparathyroidism, hyperthyroidism, hypothyroidism, diabetes mellitus, acromegaly, adrenal insufficiency), malnutrition, malabsorption, parenteral nutrition (coeliac disease, Crohn's disease, lactose intolerance, after gastrectomy or intestinal resection, liver diseases), rheumatologic or systemic/inflammatory disorders (rheumatoid arthritis, ankylosing spondylitis, systemic lupus erythematosus, juvenile idiopathis arthritis, amyloidosis, sarcoidosis), renal insufficiency, hematologic disorders (multiple myeloma, monoclonal gammopathies, lymphoma and leukemia, hemophilia, thalassemia), some inherited disorders (osteogenesis imperfecta, Marfan syndrome, hemochromatosis, hypophosphatasia, homocystinuria, porphyria), scoliosis of unknown cause, Parkinson's disease, chronic obstructive pulmonary disease, oncology diseases, some chronic medication (glucocorticoids, barbiturates, phenytoin, antiepileptics, L-thyroxin, aromatase inhibitors, methotrexate, anticoagulants, proton pump inhibitors, antacids, lithium, antidiabetics).

\section{Metabolic syndrome}

Metabolic syndrome is a combination of medical disorders that significantly increase the risk of developing cardiovascular disease, stroke and type 2 diabetes mellitus. There are currently 3 major definitions for metabolic syndrome (Tabs 2 and 3 ).

\section{Vitamin D}

Vitamin D influences bone metabolism in a complex way and has an essential role in the normal development of the skeleton. As well as the dietary intake, the synthesis of vitamin $\mathrm{D}_{3}$ (cholecalciferol) in skin by sunlight is the main source of vitamin D in humans. Following hydroxylation in the liver, it is transformed into 25-hydroxy (25-OH) vitamin $\mathrm{D}_{3}$ and then, in the kidneys, 1,25-dihydroxy vitamin $\mathrm{D}_{3}$ and 24,25-dihydroxy vitamin $\mathrm{D}$ are synthesised via relevant hydroxylases (see the scheme bellow). The bone and intestines are the main target organs of calcitriol. Vitamin D plays an important role in calcium homeostasis. A number of cells possess receptors for vitamin D and so this is the reason of its other functions $(2,5)$ (Fig. 1).

The concentration of $25(\mathrm{OH})$ vitamin $\mathrm{D}_{3}$ is a relevant indicator of the total vitamin D status in the body as it represents the amount of vitamin D synthesised and ingested. The recommended daily intake of vitamin D is approximately $800 \mathrm{IU}$ and over 1000 IU for treatment. Some authors recommend even higher doses. A daily intake up to 2000 IU is generally considered safe (2). The main regulator of vitamin D levels is PTH (parathormone) and hypocalcemia, which increases its secretion. Other regulators are growth hormone, prolactine and sex hormones (7).

\section{Main functions of vitamin D (7):}

1. regulation of calcium and phosphorus levels in blood,

2. bone metabolism,

3. inhibition of PTH secretion,

4. immunomodulatory effect,

5. prevention and treatment of oncology diseases,

6. effect in metabolic syndrome and cardiovascular diseases.

\section{Methods}

The aim of our study was to evaluate the relationship between bone mineral density, body fat percentage, vitamin $\mathrm{D}_{3}$ levels and signs of metabolic syndrome.

We examined 55 subjects ( 37 women, 18 men, age median 67.8 years) with no history of osteoporosis, suffering from metabolic syndrome (defined as abdominal obesity and more than 2 of other components - arterial hypertension, dyslipidemia and diabetes mellitus or impaired glucose tolerance, according to IDF, 2006) (Tab. 4).

The bone mineral density (in lumbar spine and hip) and body fat was examined by DXA - dual energy x-ray absorptiometry (Hologic - Discovery) and vitamin $\mathrm{D}_{3}$ levels by electrochemiluminiscence immunodetection. The Spearman rank order correlation analysis has been used.

\section{Results}

Osteoporosis (T-score less than -2.5) was found in $32.7 \%$ (15 women and 3 men) and osteopenia (T-score between -1.5 and -2.5 ) 


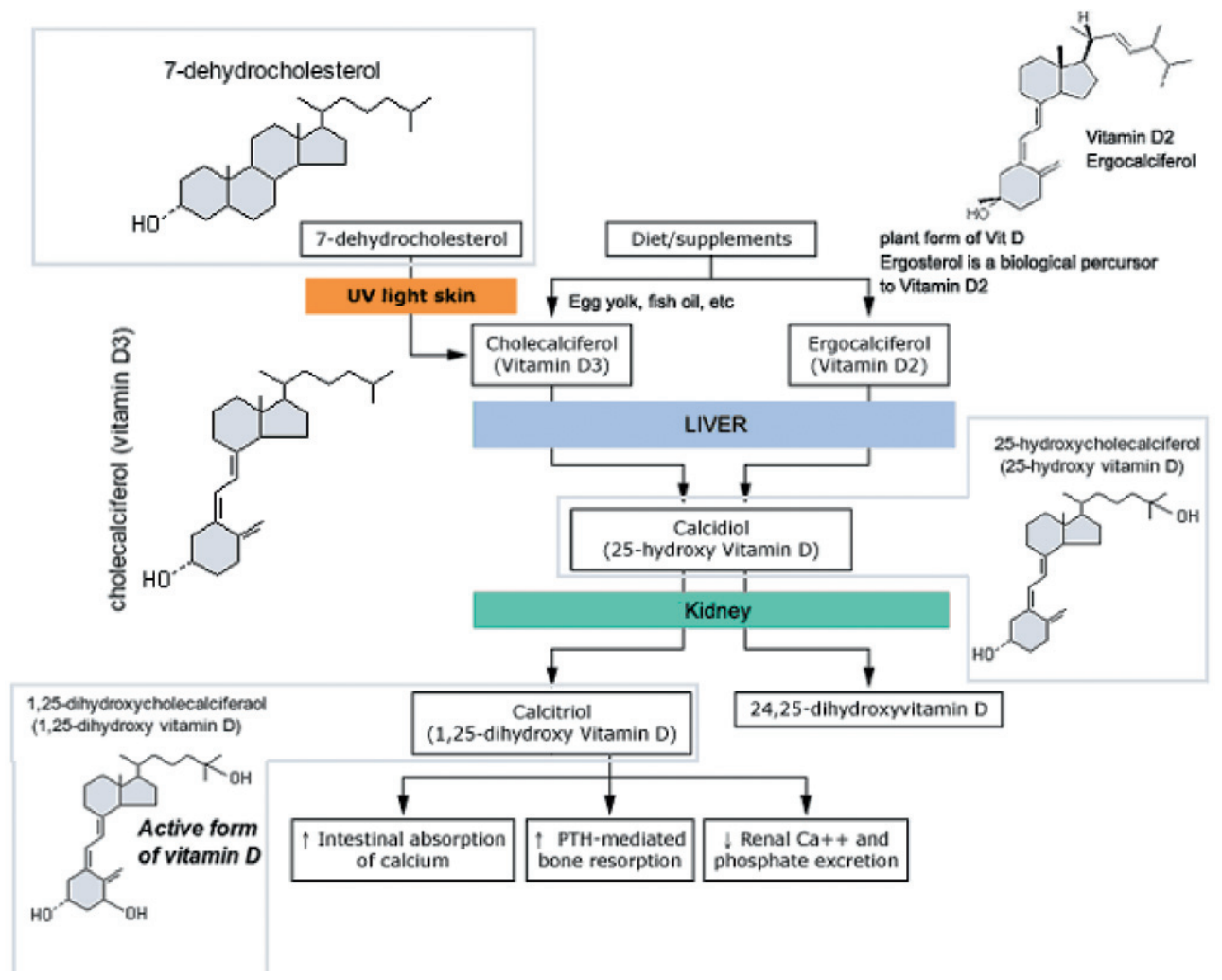

Fig. 1. Vitamin D metabolism (6).

in $29 \%$ (13 women and 3 men) of patients. We observed a negative correlation between BMI and fat percentage (examined by DXA) and vitamin $\mathrm{D}_{3}$ levels. Low concentration of vitamin $\mathrm{D}_{3}$ was found in $90 \%$ of patients with the median $19.36 \mathrm{ug} / 1$ (64 \% measured in winter, $36 \%$ in summer, no relationship between vitamin $\mathrm{D}_{3}$ levels and season). We also observed a negative correlation between a low concentration of vitamin $\mathrm{D}_{3}$ and a presence of diabetes mel-

Tab. 4. Patients.

\begin{tabular}{ll}
\hline arterial hypertension & $89 \%$ (49 patients) \\
dyslipidemia & $87.2 \%$ (48 patients) \\
diabetes mellitus or impaired glucose tolerance & $92.7 \%$ (51 patients) \\
\hline
\end{tabular}

Tab. 5. Characteristics of patients.

\begin{tabular}{lccc}
\hline & Median & $\begin{array}{c}\text { Standard } \\
\text { deviation }(\mathrm{sd})\end{array}$ & Normal range \\
\hline Vitamin D3 & $19.36 \mathrm{ug} / \mathrm{l}$ & $7.6 \mathrm{ug} / 1$ & $30-80 \mathrm{ug} / 1$ \\
$\mathrm{Ca}$ & $2.23 \mathrm{mmol} / 1$ & $0.3 \mathrm{mmol} / 1$ & $2.1-2.55 \mathrm{mmol} / 1$ \\
cholesterol & $4.21 \mathrm{mmol} / 1$ & $1.01 \mathrm{mmol} / 1$ & $3.5-4.5 \mathrm{mmol} / 1$ \\
LDL & $2.3 \mathrm{mmol} / 1$ & $1.0 \mathrm{mmol} / 1$ & less than $1.8 \mathrm{mmol} / 1$ \\
HDL & $1.15 \mathrm{mmol} / 1$ & $0.45 \mathrm{mmol} / 1$ & $1.0-2.7 \mathrm{mmol} / 1$ \\
TAG & $1.82 \mathrm{mmol} / 1$ & $1.27 \mathrm{mmol} / 1$ & $0.45-1.7 \mathrm{mmol} / 1$ \\
BMI & $28.73 \mathrm{~kg} / \mathrm{m}^{2}$ & $4.8 \mathrm{~kg} / \mathrm{m}^{2}$ & $20-25 \mathrm{~kg} / \mathrm{m}^{2}$ \\
fat & $36.72 \%$ & $7.66 \%$ & M $18-24 \%$ \\
& & & W $25-31 \%$ \\
waist circumference & $101.72 \mathrm{~cm}^{2}$ & $11.6 \mathrm{~cm}$ & M less than $94 \mathrm{~cm}$ \\
& & & W less than $80 \mathrm{~cm}$ \\
BMD spine & $0.96 \mathrm{~g} / \mathrm{cm}^{2}$ & $0.17 \mathrm{~g} / \mathrm{cm}^{2}$ & \\
BMD hip & $0.89 \mathrm{~g} / \mathrm{cm}^{2}$ & $0.19 \mathrm{~g} / \mathrm{cm}^{2}$ & \\
\hline
\end{tabular}

litus as a part of metabolic syndrome. The relationship between vitamin $\mathrm{D}_{3}$ levels and dyslipidemia and arterial hypertension was not confirmed (Tab. 5).

\section{Discussion}

DXA is widely used by clinicians and researchers for the evaluation of bone status and soft tissue composition. With DXA, we can get information about body composition that include BMC (bone mineral content), BMD (bone mineral density), fat and other soft tissues. The underlying principle is its ability to quantify the attenuated radiation after its passage through bone and soft tissue using either K-edge filters or pulsed power sources to the x-ray tube. Subsequently, the differential attenuation of the two energies is utilized to quantify bone, lean, and/or fat tissue (8). DXA is considered one of the most precise technologies in clinical medicine with the typical coefficients of variation between 1-2\% (9). It performs whole-body scans and can be used to determine the bone and soft tissue composition of the whole body and subregions such as arms, legs, and trunk $(10,11,12)$, and it can be also used to evaluate aortic abdominal calcifications (13). The effective dose incurred during DXA scanning is very small, and, consequently, DXA is a simple and safe technique that can be used for children and the old and frail $(10,11)$.

It is supposed that the relationship between vitamin D levels and metabolic syndrome is mediated by its affect on each component of metabolic syndrome. Various researchers published the 
association between vitamin D levels and central obesity, insulin secretion, insulin sensitivity, lipidemia and also arterial hypertension (7).

Obese individuals are at a risk for a number of metabolic and endocrine abnormalities. Obese adults and overweight children have been found to have low 25-hydroxyvitamin D and this information have been confirmed by our study. Several investigators have reported that, upon binding to the vitamin $\mathrm{D}$ receptor, 1,25 -vitamin D can cause an increase in intracellular calcium that in turn can stimulate lipogenesis and inhibit lipolysis in adipocytes (14). Some studies found that low calcium and vitamin D intake are linked to obesity. We observed a negative correlation between obesity and vitamin $\mathrm{D}_{3}$ levels. Low concentration of vitamin $\mathrm{D}_{3}$ was found in $90 \%$ of patients with median $19.36 \mathrm{ug} / 1$ (64 \% measured in winter, $36 \%$ in summer, no relationship between vitamin $\mathrm{D}_{3}$ levels and season).

In population with a higher calcium and vitamin D intake, a significant decrease in prevalence of overweight, obesity and insulin resistance was observed and several studies also found a negative association between dairy calcium intake and PTH and vitamin D levels (15). With regard to calcium homeostasis, the calcium-regulating hormones vitamin D and PTH have both been shown to stimulate a significant and sustained increase in intracellular calcium concentrations. This is the main mechanism that leads to stimulation of lipolysis and inhibition of lipogenesis in adipocytes $(16,17)$. Various studies demonstrate a beneficial role for dietary calcium in the partitioning of dietary energy, resulting in reductions in body fat and an acceleration of weight and fat loss during energy restriction. Interestingly, dairy sources of calcium exert substantially greater effects than supplemental or fortified sources of calcium (17).

Hypovitaminosis D has long been suspected as a risk factor for glucose intolerance. Various studies found that vitamin D could play a role in the pathogenesis of type 2 diabetes, by affecting either insulin sensitivity or beta-cell function, or both (18). The role of vitamin D in the metabolic syndrome is suggested by a report from the Coronary Artery Risk Development in Young Adults (CARDIA) Study, a population-based prospective study. In sampling 3157 black and white adults aged 18-30 years from 4 US metropolitan areas, it was observed that dairy consumption was inversely associated with the incidence of insulin resistance syndrome among overweight adults. Subjects with the highest dairy consumption had a $72 \%$ lower incidence of the metabolic syndrome than did those with the lowest dairy intake. Therefore, dairy consumption may reduce the risk of type 2 diabetes and cardiovascular disease (19). We observed an inverse association between vitamin $\mathrm{D}_{3}$ levels and presence of diabetes mellitus.

The effect of vitamin D in pregnant patients was studied as well. Hypovitaminosis D was in the relationship with fetal betacell dysfunction and then also with insulin resistance in young children. In this study, hypovitaminosis D was observed in a 70 $\%$ of women with type 2 diabetes. After 1 month administration of cholecalciferol (1330 IU), they had normal vitamin D levels and also a significantly decreased insulin resistance (about $21 \%$ lower) (20).
Various authors suggest that increase in calcium and vitamin D intake leads to decrease of triglycerides and TG/HDL ratio, too (21). Some studies also observed the relationship between vitamin D and PTH levels and the process of atherosclerosis (AS) (22, 23). The pathogenesis of atherosclerosis shares features of skeletal bone formation: cells with osteoblast phenotype have been identified in the stenotic aortic valve, and mature lamellar bone commonly occurs in end-stage AS. It was found that an increased PTH with a lower vitamin D level was independently associated with AS in a prospectively collected sample of patients with significant coronary artery disease, and moderate to severe AS with preserved renal function. These results suggest a dysregulation of calcium-phosphate metabolism, with elevated PTH and lack of vitamin $\mathrm{D}$, as a possible pathogenetic factor in AS in patients with coronary artery disease (22).

Emerging evidence from clinical studies has demonstrated an inverse relationship between circulating vitamin D levels and the blood pressure and/or plasma renin activity, but the mechanism is yet not understood. It is suggested that the inhibition of $1,25(\mathrm{OH})_{2} \mathrm{D}_{3}$ synthesis leads to an increase in renin expression and also to the inhibition of smooth muscle cells proliferation, whereas $1,25(\mathrm{OH})_{2} \mathrm{D}_{3}$ injection leads to renin suppression. Thus, vitamin $\mathrm{D}$ is a novel negative endocrine regulator of the renin-angiotensin system $(24,25)$. Previous studies have also shown that intravenous infusion of PTH increases plasma renin activity and renin release in humans and animals, but the molecular mechanism whereby PTH regulates renin expression in vivo remains unknown. PTH may indirectly regulate renin expression in vivo (26). We didn `t evaluate a potentional connection between the serum levels of parathormone and any part of metabolic syndrome. Forman examined the independent association between the vitamin D intake and the risk of incident hypertension among participants of 3 large and independent prospective cohorts: Nurses Health Study I (NHS I, $n=77$ 436), NHS II ( $\mathrm{n}=93$ 803), and Health Professionals' Follow-up Study (HPFS, $n=38$ 074). Each cohort was followed for $>8$ years. Surprisingly, vitamin D intake was not associated with the risk of developing hypertension (27). In other studies, the association of 1,25-dihydroxyvitamin $\mathrm{D}_{3}$ and blood pressure has been shown in normotensive men, myocardial infarction was inversely associated with plasma 25-hydroxyvitamin $\mathrm{D}_{3}$ levels, and a higher blood pressure in elderly women correlated to an increased bone loss. Pfeifer demonstrated that short-term supplementation with vitamin $\mathrm{D}_{3}$ and calcium was more effective in reducing systolic blood pressure than calcium alone, and this effect is most likely to be due to the restoration of parathyroid gland function to normal (28).

\section{Conclusion}

Vitamin D deficiency is now recognised as a worldwide concern and metabolic syndrome has become a global epidemic. Various authors suggest that hypovitaminosis D may increase the risk of metabolic syndrome. According to many researchers, circulating concentrations of vitamin D may be inversely related to the prevalence of diabetes, impaired glucose tolerance, insulin resistance, arterial hypertension and lipidemia. 
412-416

An inadequate vitamin $\mathrm{D}_{3}$ and calcium intake are not only a risk for osteoporosis, but they could play a contributory role in the pathogenesis and progression of hypertension and cardiovascular disease, particularly in elderly people with vitamin D deficiency and secondary hyperparathyreoidism $(28,29)$.

The link between osteoporosis and metabolic syndrome could influence the therapeutic approach in both disorders and vitamin D supplementation may play an important role in prevention of these severe conditions.

\section{References}

1. Broulik P. Osteoporosis. Praha: Maxdorf Jessenius, 1999, 64 pp.

2. Rovensky J, Payer J (Eds). Bisphosphonates. Dictionary of Rheumatology. NewYork: SpringerWien, 2009, 24 pp.

3. Payer J, Brazdilova K, Jackuliak P. Management of glucocorticoidinduced osteoporosis: prevalence, and emerging treatment options. Drug, Healthcare and Patient Safety 2010; 2: 49-59.

4. Paula HA, Ribeiro Rde C, Rosado LE, Pereira RS, Franceschini Sdo C. Comparison of the different definition criteria for the diagnosis of the metabolic syndrome in elderly women. Arq Bras Cardiol 2010; 95 (3): $346-353$.

5. Ginter E, Simko V. Vitamin D deficiency, atherosclerosis and cancer. Bratisl Lek Listy 2009; 110 (12): 751-756.

6. National Institutes of Health. Dietary supplement fact sheet: Vitamin D. 2009.

7. Brazdilova K, Payer J. Relationship between metabolic syndrome and vitamin D and calcium. Osteol Bull 2008; 13: 57-64.

8. Brownbill RA, Ilich JZ. Measuring body composition in overweight individuals by dual energy $\mathrm{x}$-ray absorptiometry. BMC Med Imaging 2005; 5: 1 .

9. Cummings SR, Palermo L, Browner W et al. Monitoring osteoporosis therapy with bone densitometry: misleading changes and regression to the mean. Fracture Intervention Trial Research Group. JAMA 2000; 283: 1318-1321.

10. Laskey MA. Dual-energy X-ray absorptiometry and body composition. Nutrition 1996; 12: 45-51.

11. GE Healthcare. Total body data and regional results. 2007.

12. Diessell E. Evaluation of a new body composition phantom for quality control anf cross-calibration of DXA devices. J Appl Physiol 2000; 89: 599-605.

13. Brazdilova K, Killinger Z, Payer J. Potential use of total body densitometry in metabolic syndrome patients - body fat measurements. Osteol Bull 2010; 15 (1): 26-29.

14. Parikh SJ, Edelman M, Uwaifo GI, Freedman RJ, Semega-Janneh M, Reynolds J, Yanovski JA. The Relationship between obesity and serum 1,25-dihydroxy vitamin $\mathrm{D}$ concentrations in healthy adults. J Clin Endocrinol Metab 2004; 89: 1196-1199.
15. Kamycheva E, Sundsfjord J, Jorde R. Serum parathyroid hormone level is associated with body mass index, the 5th Tromso study. Eur J Endocrinol 2004; 151: 167-172.

16. Parikh SJ, Yanovski JA. Calcium intake and adiposity. Am J Clin Nutr 2003; 77: 281-287.

17. Zemell MB. Mechanisms of dairy modulation of adiposity. J Nutr 2003; 133: 252-256.

18. Chiu KC, Chu A, Go VL, Saad MF. 25-Hypovitaminosis D is associated with insulin resistance and $\beta$ cell dysfunction. Am J Clin Nutr 2006; 79: 820-825.

19. Pereira MA, Jacobs DRJ, Van Horn L, Slattery ML, Kartashov AI, Ludwig DS. Dairy consumption, obesity, and the insuline resistance syndrome in young adults: the CARDIA Study. JAMA 2002; 287: 2081-2089.

20. Kalvachova B. New perspectives on vitamin D and its importance for the organism. In: Starka L. Advances in endocrinology. Praha: Maxdorf Jessenius, 2007; 113-128.

21. Pimentel GD, Arimura ST, de Moura BM, Silva ME, de Sousa MV. Short-term nutritional counseling reduces body mass index, waist circumference, triceps skinfold and triglycerides in women with metabolic syndrome. Diabetol Metab Syndr 2010; 10: 2-13.

22. Linhartova K, Veselka J, Sterbakova G, Racek J, Topolcan O, Cerbak R. Parathyroid hormone and vitamin D levels are independently associated with calcific aortic stenosis. Circulat J 2008; 3: 1483.

23. Zofkova I. Osteoporosis and atherosclerosis - is a pathogenetic link between them? Čas Lék Čes 2007; 146: 246-250.

24. Li YC, Kong J, Wei M, Chen ZF, Liu SQ, Cao LP. 1,25-Dihydroxyvitamin $\mathrm{D}_{3}$ is a negative endocrine regulator of the renin-angiotensin system. J Clin Invest 2002; 110: 229-238.

25. Sigmund CD. Regulation of renin expression and blood pressure by vitamin D3. J Clin Invest 2002; 110: 155-156.

26. Broulik PD, Horky K, Pacovsky V. Effect of parathyroid hormone on plasma renin activity in humans. Horm Metab Res 1986; 18 (7): 490-492.

27. Forman JP, Bischoff-Ferrari HA, Willett WC, Stampfer MJ, Curhan GC. Vitamin D intake and risk of incident hypertension, results from three large prospective cohort studies. Hypertension 2005; 46: 676682.

28. Pfeifer M, Begerow B, Minne HW, Nachtigall D, Hansen C. Effects of a short-term vitamin D3 and calcium supplementation on blood pressure and parathyroid hormone levels in elderly women. J Clin Endocrinol Metab 2001; 86: 1633-1637.

29. Zemel MB. Calcium modulation of hypertension and obesity: Mechanisms and implications. J Am Coll Nutr 2001; 20: 428-435.

Received November 17, 2010. Accepted April 15, 2012. 